\title{
Cuidados paliativos oncológicos: reflexões sobre uma proposta inovadora na atenção à saúde*
}

Palliative care in cancer: considerations on an innovative proposal in health care

Autor: Ronaldo Corrêa Ferreira da Silva

Orientadores: Prof ${ }^{a}$. Dr ${ }^{a}$. Virginia Alonso Hortale e Dr. Paulo Roberto Vasconcellos-Silva

\begin{abstract}
Resumo
A partir de publicações que identificam o câncer como um problema de saúde pública, considerando que em muitos países economicamente menos desenvolvidos os cuidados paliativos podem ser a única opção de cuidado oferecido, e que são poucas as publicações sobre este tema nestes mesmos países, acreditamos ser essencial a discussão sobre cuidados paliativos em nosso país. Por meio de uma revisão bibliográfica, podemos estabelecer um referencial teórico para as reflexões sobre esta proposta inovadora na atenção à saúde. A análise do material indica que os cuidados paliativos encontram-se estruturados nos países economicamente desenvolvidos, mas que ainda estão em fase de implementação nos países economicamente menos desenvolvidos. N estes, programas e serviços que respeitem as culturas e as crenças de cada país têm maior possibilidade de sucesso do que programas não adaptados. Para adaptá-los, questões como uma melhor compreensão dos conceitos de cuidado, morte e finitude em nossa sociedade são essenciais. Como resultado destas reflexões, emergem al guns objetivos a serem alcançados: possibilitar os indivíduos a realizarem suas escolhas; discutir amplamente com a sociedade o papel do cuidador e de medidas de suporte social ao mesmo; reivindicar a inserção no ensino médico de disciplinas que discutam a morte e o morrer e oferecer um cuidado integral para o indivíduo ao final da vida, isto é, atendendo as dimensões físicas, emocionais, espirituais, sociais e econômicas.
\end{abstract}

Palavras-chave: Cuidados paliativos, cuidados a doentes terminais, cuidados médicos, cuidados domiciliares de saúde

*D issertação apresentada com vistas à obtenção de título de M estre em Ciências na Área de Saúde Pública, em março de 2004.

E-mail: rsilva@inca.gov.br 